\title{
Acute Abdomen in Adult Revealing Unusual Complicated Epiploic Appendagitis: A Case Report
}

yahya charifi ( $\nabla$ y.charifi92@gmail.com )

Centre Hospitalier Universitaire Hassan II - Fes https://orcid.org/0000-0002-7008-7346

alaoui lamrani My Youssef

Centre Hospitalier Universitaire Hassan II - Fes

Chbani Laila

Hassan II University Hospital in Fez: Centre Hospitalier Universitaire Hassan II - Fes

\section{Boubbou Meryem}

Centre Hospitalier Universitaire Hassan II - Fes

Maaroufi Mustapha

Centre Hospitalier Universitaire Hassan II - Fes

Badreddine Alami

Centre Hospitalier Universitaire Hassan II - Fes

\section{Case report}

Keywords: pathology, Epiploic Appendagitis, surgery

Posted Date: September 8th, 2020

DOl: https://doi.org/10.21203/rs.3.rs-46880/v1

License: (c) (i) This work is licensed under a Creative Commons Attribution 4.0 International License. Read Full License

Version of Record: A version of this preprint was published at International Journal of Surgery Case Reports on January 1st, 2020. See the published version at https://doi.org/10.1016/j.ijscr.2020.09.041. 


\section{Abstract}

BACKGROUND Epiploic appendagitis is a torsion of fatty appendages of ligamentum trees (1), its a rare cause of abdominal pain that usually manifests by right or left iliac fossa pain, reminding of appendicitis, diverticulitis or ischemia of the omentum.

CASE PRESENTATION We report the case of a 56 years old male patient admitted for an epigastric pain and a right-upper quadrant abdominal pain, for whom he underwent an abdominal ultrasound and a CTscan who shown an abscessed mass under colic transverse to the unusual seat. CT scan is still the key modality for diagnosis, avoiding unnecessary surgery. Complications of primary epiploic appendagitis have rarely been described in the literature. Another more rare complication is appendagitis with associated abscess, in this condition, we must also think about complicated diverticulitis. The treatment of uncomplicated forms is generally conservative, however, some authors have suggested a surgical method. For therapeutic management of its complication, there has been much interest in the use of minimally invasive techniques such as percutaneous drainage to minimize the morbidity and mortality that is associated with surgery.

CONCLUSION The diagnosis of epiploic appendagitis is still uncommon, CT scan, can eliminate other diagnosis of acute abdominal pain such as diverticulitis and appendicitis. It also allows the diagnosis of the rare complicated forms such as abscesses associated with epiploic appendagitis. The treatment of typical forms is usually conservative, while the complicated form requires surgery because of the potential associated pathology.

\section{Background}

The epiploic appendix is a fatty structure covered with peritoneum and containing vessels from the colonic vasculature [1]. There are about 100 in all, more common are on the sigmoid and cecum. They are more prevalent and larger in obese patients [2]. Primary epiploic appendagitis is frequent [3] and corresponds to the inflammation of an epiploic appendix spontaneously or potentially by torsion or ischaemia. The clinical and biological aspects are non-specific [4]. They often suggest ileocaecal appendicitis or diverticulitis. Our work is focused on an uncommon complication of epiploic appendagitis which is abscess and it follows perfectly the SCARE criteria (11).

\section{Case Presentation}

56 years old male, obese, smoker since 20 years, without occupation, admitted in our structure for epigastric and right hypochondriac pain progressing since one week with a 5 days of sub occlusive syndrome. The initial clinical examination showed epigastric and right hypochondriac sensibility associated with a fever reaching $38.5^{\circ}$.

Biology revealed hyperleukocytosis at 13,000 elements/mm3 associated with a raised $\mathrm{C}$ reactive protein at $57 \mathrm{mg} / \mathrm{l}$. 
An emergency abdominal ultrasound examination was performed and revealed a left supra-umbilical pseudo-mass , containing multiple partitions with significant fat and infiltration all around (figure 1).

The patient had an abdominal CT scan with contrast injection, which showed a rounded formation at the expense of the large supra-umbilical omentum slightly lateralized on the left, under the transverse colon, which had a low-density, with thin septas inside, a regular wall and peripheral contrast enhancement. It is associated with a significant local infiltration. The appendix had a normal morphology: there was no intestinal occlusion (figure 2).

The surgeons indicated an exploration by midline laparotomy, and not radiological drainage, considering the clinical peritonitis and also the suspicion of ulcer perforation due to the patient's smoking history , even without pneumoperitoneum, its revealed an inflammatory epiploic mass, associated with a single microbial abscess, without any abnormalities of the gastrointestinal wall, so surgical excision of the mass was performed, and then the surgical piece was sent for anatomo-pathological study. The postoperative status was normal without immediate or late complications; the patient received antibiotic therapy with good clinical evolution.

One week after his hospitalization, the biological results improved with a hemoglobin level from 10.3 to $12 \mathrm{~g} / \mathrm{dl}$, leukocytes from 13,000 elements/mm3 to 11,000 elements/mm3 without significant variation in other parameters.

The microbiological results of the collection revealed that it was a sterile abscess, with no isolated germ.

The anatomopathological study of the pseudo-mass showed a macroscopic appearance of a fibrinoleukocyte layer (figure 3). The microscopic study showed altered fibrin and polynuclear tissue around the fat (figure 4).

\section{Discussion And Conclusions}

Epiploic appendagitis also known as "appendicitis epiploica" or "appendagitis," results from an inflammation of the epiploïc appendix and is usually characterized by acute abdominal pain with localized defense. This symptomatology is due to the torsion-necrosis of an epiploïc fringe [5], which is a small ( 0.5 to $5 \mathrm{~cm}$ length, 1 to $2 \mathrm{~cm}$ wider) sub peritoneal fat formation composed of a duplication of the visceral peritoneum covering the colon. It involves the entire colon, including 50 to 100 appendixes which are distributed in order of frequency as follows: recto sigmoid (57\%), ileocaecal area (26\%), ascending colon (9\%), transverse colon (6\%), and descending colon (2\%) [8].

The vascularization of an epiploic fringe is provided by 1 or 2 small arteries. The pedicular and mobile nature of these epiploic fringes leads to torsion on their axis, resulting to vessel thrombosis, ischemia and necrosis. Thrombosis of the own vessels can also occur and induce the same ischemic and necrotic effects $[5,6,8]$. 
In pathophysiology, a distinction is made between primary appendagitis when torsion or thrombosis occurs spontaneously and secondary appendagitis when it results from the spread of inflammation from nearby organs, especially in cases of diverticulitis, appendicitis or pancreatitis [7].

It is a rare pathology frequently diagnosed by laparotomy or laparoscopy [5]. The mean age of appearance is 35 years with a sex ratio close to 1 . The clinical signs are not specific. The anamnesis reports constant pain, which may be of the grinding or colic type. Diarrhea is found in $25 \%$ of cases, moderate fever in $15 \%$ of cases [4]. Clinical examination reveals intense pain on palpation or even localized defense as we seen in our case [3]. In most cases, this clinical presentation may mimic other pathological conditions, such as acute appendicitis and diverticulitis (16).

Atypical signs such as respiratory symptoms can be found in cases of appendagitis on the transverse colon as observed in our study or at the angles of the colon, and exceptionally may simulate clinical forms of cholecystitis $[4,5]$.

Biologically, appendagitis is not associated with biological changes such as hyperleukocytosis or inflammatory syndrome, however changes in these parameters may not necessarily mean that the diagnosis is excluded, but they may suggest complications such as an epiploic abscess, as in the current case $[4,8]$.

Our patient was obese with a body mass index (BMI) of $30 \mathrm{~kg} / \mathrm{m} 2$, so the ultrasound examination was difficult, however, we visualized a pseudo-mass, ovoid, non-compressible in the painful area, surrounded by a hyperechoic peripheral halo, and these aspects were compatible with those described in the literature [5].

CT scan is still the key modality for diagnosis, avoiding unnecessary surgery, by showing on unenhanced CT images a solitary mass adjacent to the colon, ovoid in a "shuttle" shape, with a higher density than normal peritoneal fat, surrounded by a high-density border [ $1 \mathrm{~mm}$ thik ] that shows inflammation of the visceral peritoneum covering the epiploic appendage, a peripheral fat infiltration is usualy associated with the mass.

A central high density focus can be seen as a "dot sign" appearance, which is highly suggestive of venous thrombus within an inflamed epiploic appendage $[7,8]$. Post-contrast CT images do not show any enhancement of the epiploic appendagitis or adjacent peritoneum.

Generally, the treatment of uncomplicated forms is conservative, and requires an observation for 24 hours , analgesic and hypocaloric diet. However, some authors have suggested that the surgical method of ligation and excision of inflamed epiploid appendages is the only way to prevent recurrence (16).

Complications of primary epiploic appendagitis have rarely been described in the literature $(14,15)$. In fact, the inflammatory process can sometimes cause adhesions and lead to obstruction of the small bowel and therefore require surgical treatment. Another more rare complication is appendagitis with associated abscess, in this condition the diagnosis of epiploic appendagitis secondary to complicated 
diverticulitis should be sought. For therapeutic management of this complication, there has been much interest in the use of minimally invasive techniques such as percutaneous drainage to minimize the morbidity and mortality that is associated with surgery. However, no clear guidance is currently available to suggest which patients should undergo percutaneous drainage versus surgery (12). Although, laparoscopy or midline laparotomy are necessary on unexpected diagnosis if acute appendicitis or diverticulitis were suspected such as in our case $[8,16,17]$.

An anatomo-pathological study of the operating epiploic appendagitis with abscess usually reveals inflammatory changes, the presence of fibrin and neutrophil polynuclear cells, with associated peritoneal reaction including congestion, oedema, and bleeding in the peripheral fat area; also some fibrinoleukocyte exudates on the surface of abcess. (10)

The diagnosis of epiploic appendagitis is still uncommon, however, it is important that a clinician can consider it based on the different imaging modalities available especially abdominal CT scan, which allows to eliminate other conditions presenting as acute abdominal pain such as diverticulitis and appendicitis. It also allows the diagnosis of the rare complicated forms such as abscesses associated with epiploic appendagitis.

The treatment of typical forms is usually conservative, while the complicated form requires surgery because of the potential associated pathology

\section{Abbreviations}

CT : Computerized Tomography

BMI : Body Mass Index

\section{Declarations}

The authors do not declare any conflict of interest

\section{Ethics approval and consent to participate}

Not applicable

\section{CONENT INFORMATION}




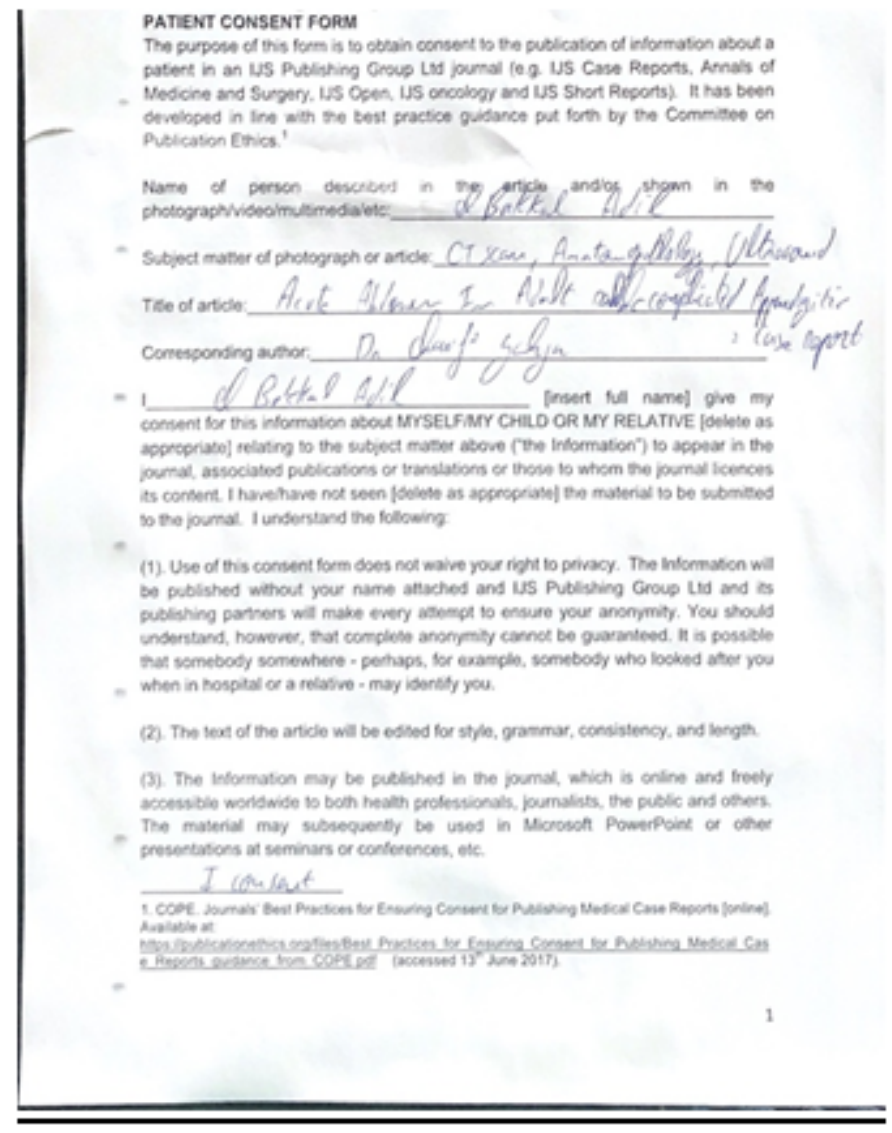

Page $6 / 13$ 
(4). You can revoke your consent at any tme before publication, but once the Information has been committed to publication ("gone to press") it will not be possible to revoke the consent.

(5). Patients and their family should note, they cannot normally expoct to derwe any inancial benefit from the publication $d$ the case. If there is any financial or material benefit, this should be staled here:

(0). It sgring tor a tamily or other group. Vwe attest hat all relevant members of the

(6). If signing for a family or other group, Uwe attest that all relevant members of the family or group have been informed.

(7). An oxiginal of the signed form will be held at the treating instoution and the authors may be required to prove that consent was cotained.

(8). If proxy consent has been obtained, i.e. the patient doesn't have legal, mental of physical capacity to consent e.g. children, persons with cognitive or intellectual disablities or deceased persons, then that should be explained here:

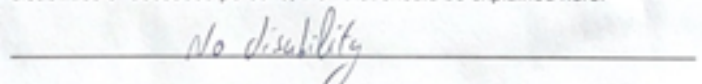

(9). The author taking consent attests that the treatment of the patient was in line with the Declaration of Helsink 2013 and was line with institutional and nasionally. acceptable practice. The author attests that an informed consent process was followed when this form was completed, with the patientirelative given sufficient time to consider its implications and the permanency of publication.

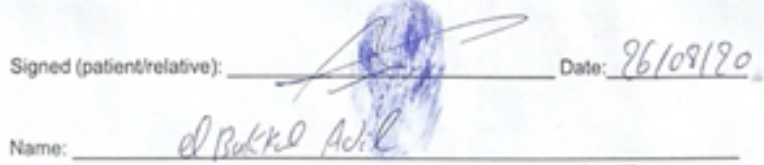

Name: e Buekel Adil
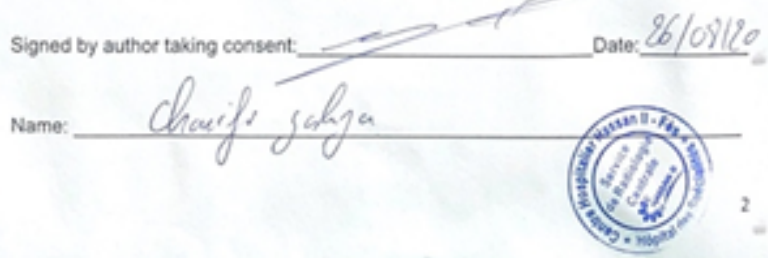

Oral and signed consent was obtained from the patient concerned.

The study was conducted anonymously

\section{Availability of data and materials}

The data sets are generated on the data system of the CHU hassan II of Fes, including the biological data, the operative report, and the data of the anatomopathological analysis

\section{Competing interests}

The authors declare that they have no competing interests

\section{Funding}

No source of funding was received

\section{Authors' contributions}

$\mathrm{CY}$, and $\mathrm{HH}$ performed and interpreted the patients CT scan and ultrasound. OA's service did surgical procedure on the patient and the data are led to the pathology performed by $\mathrm{CL}$, and the professor $A B$ 
was a major contributor in writing the manuscript. All authors read and approved the final manuscript.

\section{Acknowledgements}

Special appreciation to Professor Boubbou Meryem, Professor Haloua Meryem, Doctor Hajar Habibi and the team of the surgical and anatomopathological department.

\section{Author's information:}

1. Charifi : y.charifi92@gmail.com, Service de Radiologie, CHU HASSAN II Fès

Y.Lamrani , radiology department youssefalaouilamrani@gmail.com

1. Chbani (2),anatomopathology department mail : chbanniml@gmail.fr

M.Boubbou (1) Radiology department : merylee78@gmail.fr

M.Maaroufi (1) Radiology department, dr_mstph@gmail.com

B.Alami(1).,radiology department alamibadr@ymail.fr

\section{References}

1. "Torsion of the Fatty Appendage of the Ligamentum Trees "Journal of the Royal College of Surgeons of Edinburg. 1975, 20, 121-122

2. Thomas JH, Rosato FE, Patterson LT. Epiploic appendagitis. Surg Gynecol Obstet. 1974;138(1):23-25.

3. Rioux M, Langis P. Primary epiploic appendagitis: clinical, US, and CT findings in 14 cases. Radiology. 1994;191(2):523-526. doi:10.1148/radiology.191.2.8153333

4. Gomez MA, Bretagnol F. Les appendagites épiploïques primitives: un diagnostic radiologique [Epiploic appendagitis: a radiologic diagnosis]. J Chir (Paris). 2002;139(6):328-331Bas du formulaire

5. Kianmanesh R, Abdullah B, Scaringi S, et al. Appendagite épiploïque primitive: un diagnostic non chirurgical souvent méconnu [Primary epiploic appendagitis: a nonsurgical and often misdiagnosed pathology]. Presse Med. 2007;36(2 Pt 1):247-250. doi:10.1016/j.lpm.2006.11.002

6. Baadh AS, Singh S, Graham RE."A mysterious cause of a surgical abdomen". The Journal of Emergency Medicine 2013; 44:336-9 doi:10.1016/j.jemermed.2012.01.06.

7. Bonnefoy S, Corberand D, Sinayoko L, Harnois F, Mennecier D, Thiolet C. Appendagite épiploique primitive : à propos d'un cas. Gastroentérol Clin Biol 2008; 32:1092-4. 
8. Kras E, Brun A, Bertrand B, Luigi S. Appendagite : un diagnostic différentiel d'abdomen chirurgical aigu [Epiploic appendagitis: a differential diagnosis of acute abdominal pain needing surgery]. Presse Med. 2013;42(3):357-360. doi:10.1016/j.lpm.2012.04.015

9. Schnedl WJ, Krause R, Tafeit E, Tillich M, Lipp RW, Wallner-Liebmann SJ. Insights into epiploic appendagitis. Nat Rev Gastroenterol Hepatol. 2011;8(1):45-49. doi:10.1038/nrgastro.2010.189

10. Servide d'anatomo-pathologie du CHU Pitié-Salpêtrière,"TP d'anatomie pathologique" dissection de l'appendicite aigue.

11. Agha RA, Borrelli MR, Farwana R, Koshy K, Fowler A, Orgill DP, For the SCARE Group. The SCARE 2018 Statement: Updating Consensus Surgical CAse REport (SCARE) Guidelines, International Journal of Surgery 2018;60:132-136.

12. Evidence National Guideline Centre (UK). Evidence review for percutaneous drainage versus resectional surgery for the management of abscesses: Diverticular disease: diagnosis and management: Evidence review N. London: National Institute for Health and Care Excellence (UK); 2019 Nov. (NICE Guideline, No. 147.)

13. Moreno Obregón F, Bermúdez López C, León Jiménez D, Ugarriza Lado E. Epiploic appendagitis as unusual cause of acute abdominal pain: Clinical and radiologic features of 7 patients. Apendagitis epiploica como causa inusual de dolor abdominal agudo: características clínicas y radiológicas de 7 pacientes. Rev Clin Esp. 2019;219(9):517-520. doi:10.1016/j.rce.2019.07.010

14. Hwang JA, Kim SM, Song HJ, et al. Differential diagnosis of left-sided abdominal pain: primary epiploic appendagitis vs colonic diverticulitis. World J Gastroenterol. 2013;19(40):6842-6848. doi:10.3748/wjg.v19.i40.6842

15. Hasbahceci M, Erol C, Seker M. Epiploic appendagitis: is there need for surgery to confirm diagnosis in spite of clinical and radiological findings?. World J Surg. 2012;36(2):441-446. doi:10.1007/s00268-011-1382-2.

16. Saad J, Mustafa HA, Elsani AM, Alharbi F, Alghamdi S. Primary epiploic appendagitis: reconciling CT and clinical challenges. Indian J Gastroenterol. 2014;33(5):420-426. doi:10.1007/s12664-014-0466-y

17. Aurello P, Petrucciani N, D'Angelo F, Romano C, Balesh A, Ramacciato G. Management of primary epiploic appendagitis in the laparoscopic era. Am Surg. 2012;78(2):112-114.

\section{Figures}




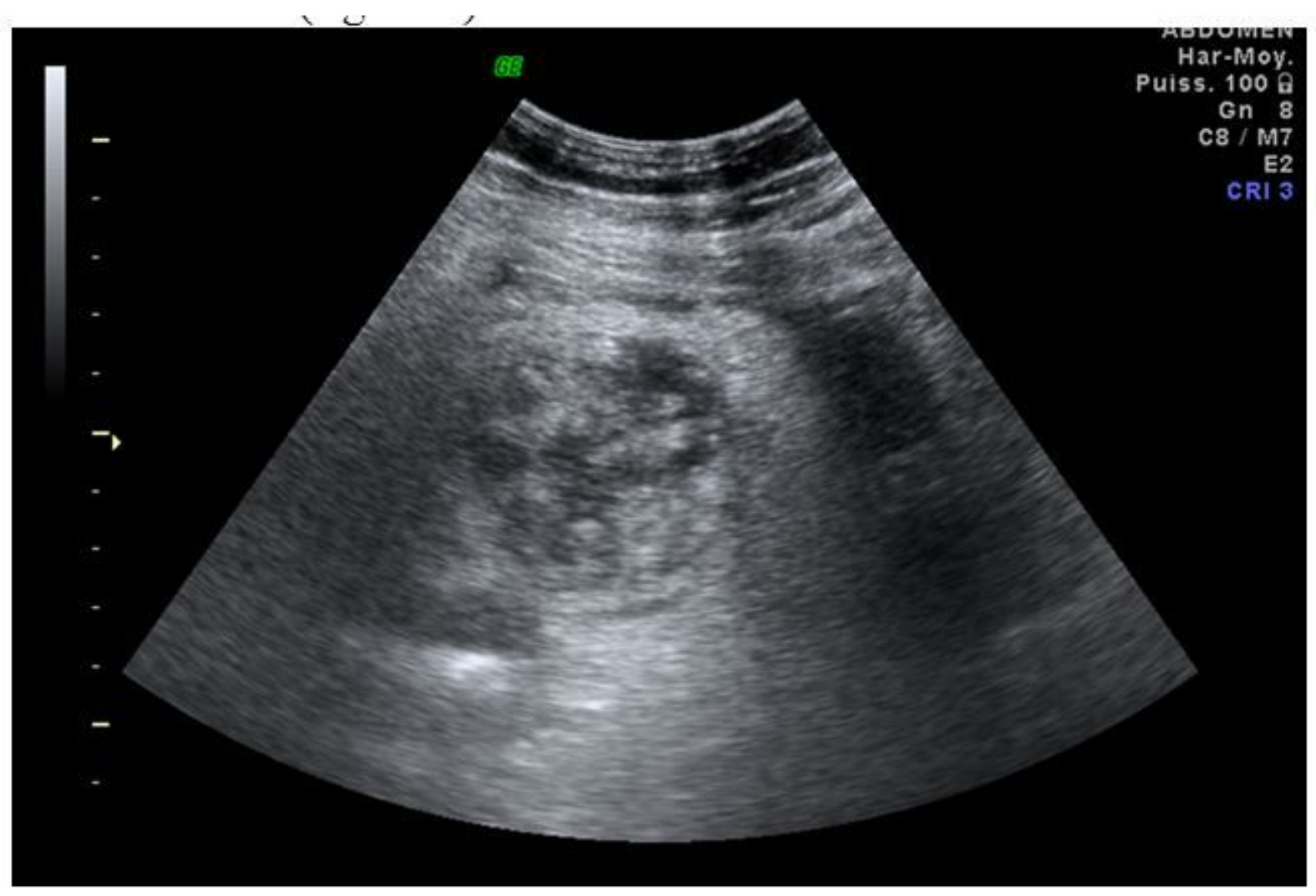

\section{Figure 1}

Ultrasound picture (using a low-frequency probe) showing a low echogenic, heterogeneous, thick-walled, regular formation with a significant infiltration of the adjacent area. 


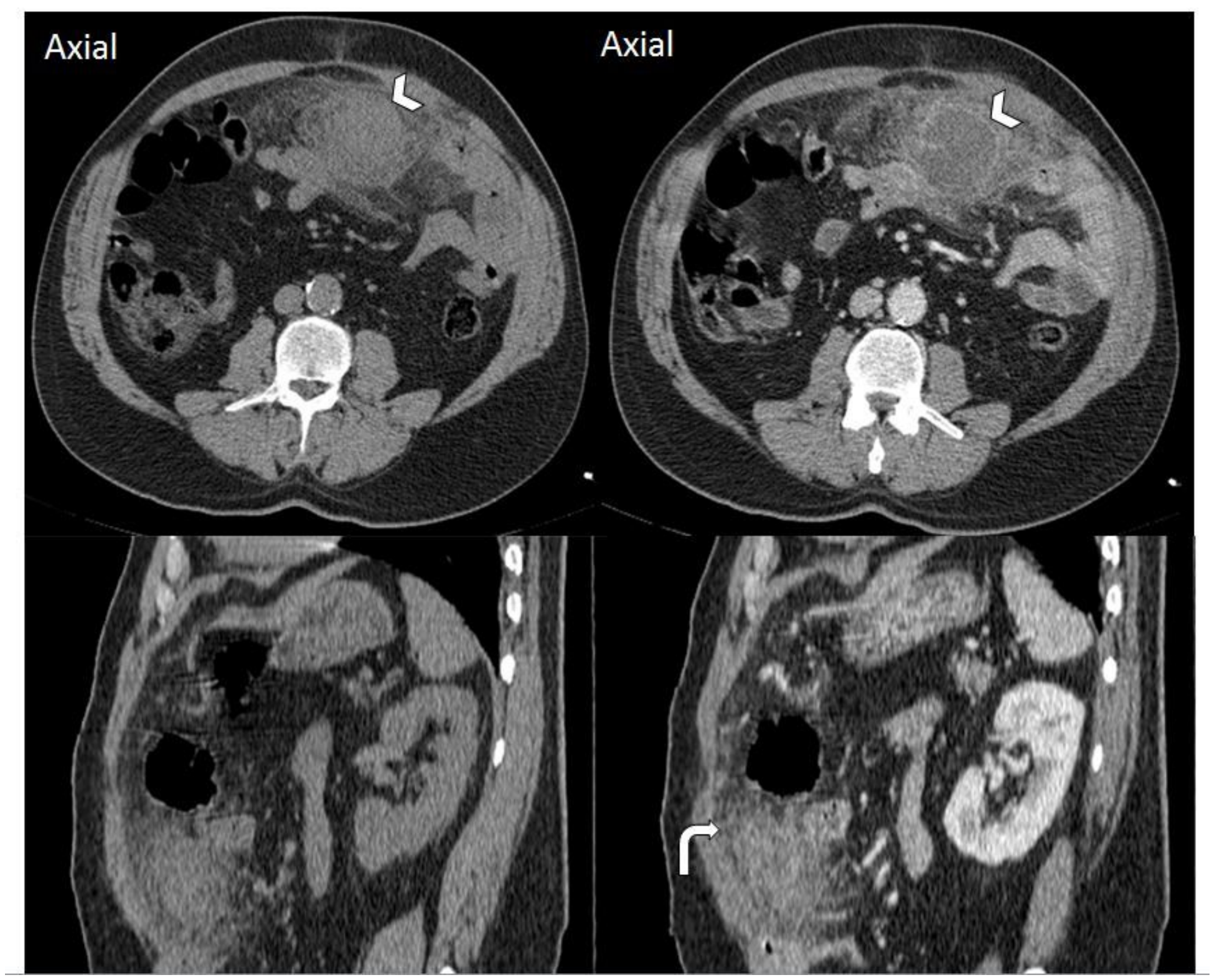

Figure 2

CT Scan images in axial and sagittal views before and after injection of contrast agent showing a supraumbilical formation (arrowhead), rounded, with low density, and regular wall, enhanced after contrast, containing some fine septa. It is associated with significant local infiltration (curved arrowhead). 


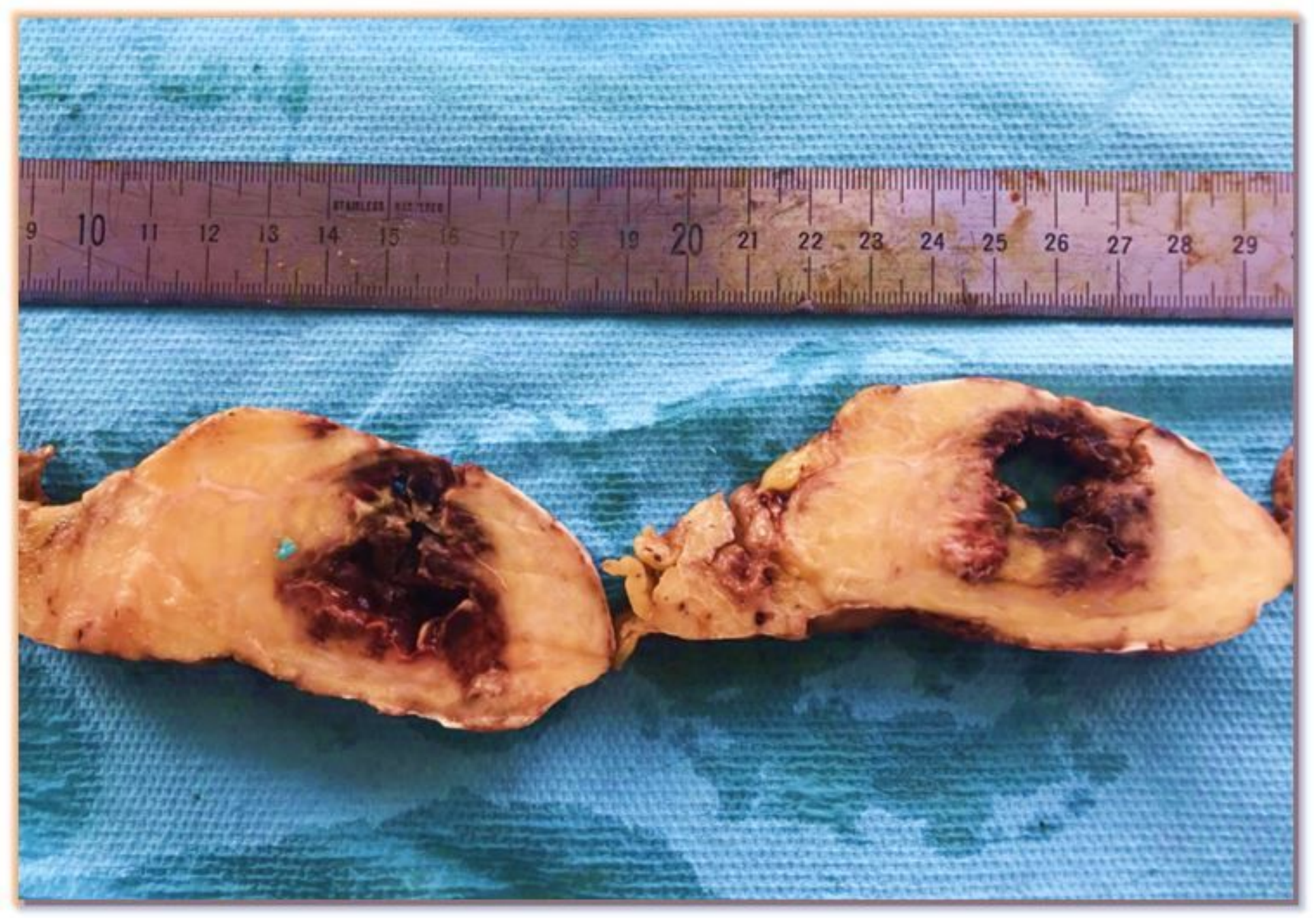

\section{Figure 3}

Macroscopy: fibrino-leukocyte layer 


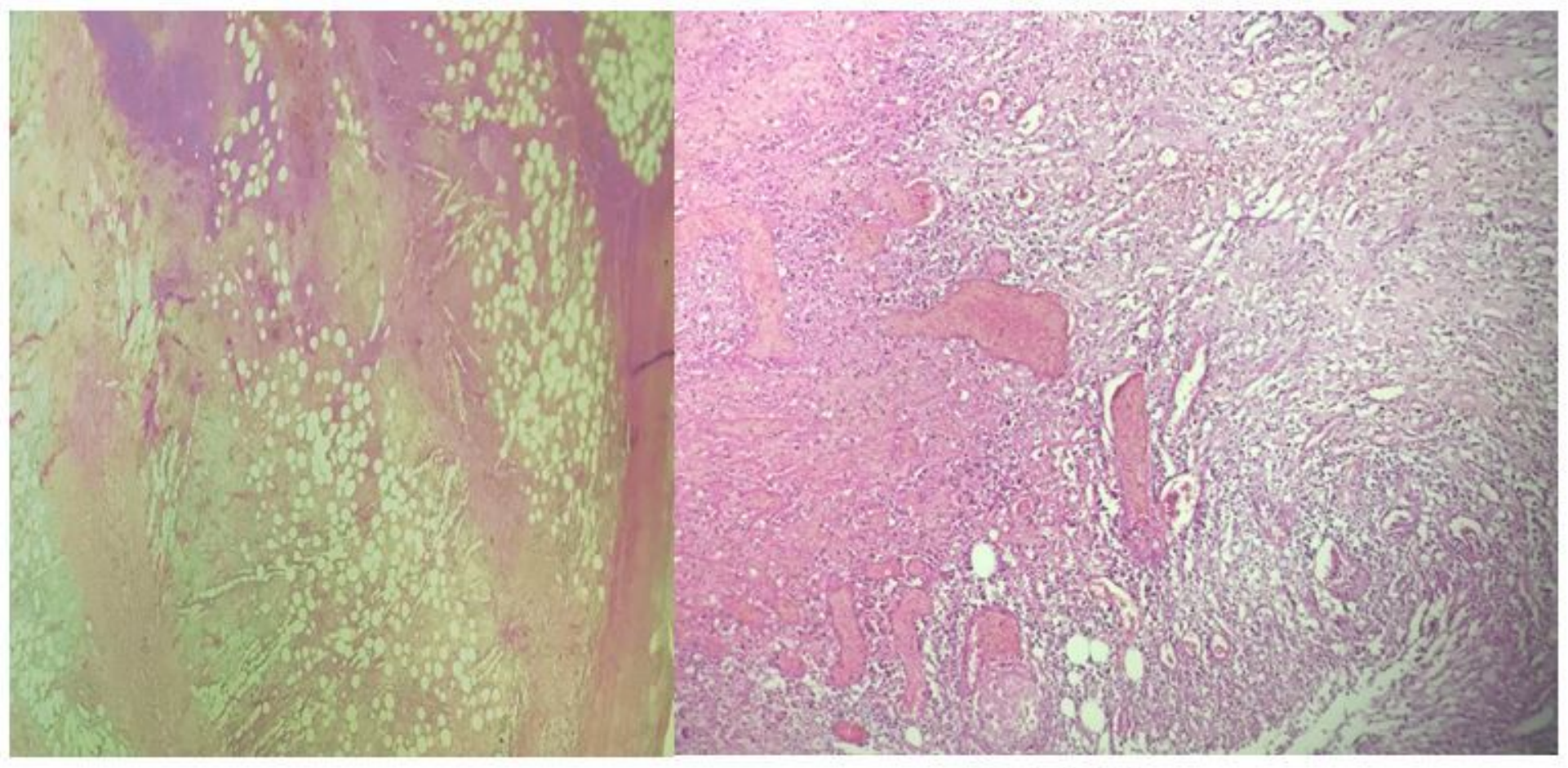

HESx100

HES 200

\section{Figure 4}

Microscopy: damaged fibrin and polynuclear tissue around fat.

\section{Supplementary Files}

This is a list of supplementary files associated with this preprint. Click to download.

- AJESjournalcoverlettertemplate.docx

- AJESjournalcoverlettertemplate.docx 